\title{
JANE AUSTEN E A RECODIFICAÇÃO PARÓDICA DO GÓTICO EM NORTHANGER ABBEY
}

Genilda Azerêdo

Universidade Federal da Paraíba

\begin{abstract}
Resumo
O objetivo deste trabalho é discutir as construções e efeitos do diálogo paródico que o romance Northanger Abbey (1818), de Jane Austen, estabelece com a tradição de literatura Gótica no contexto inglês do século XVIII. Por ser considerada uma forma expressiva de intertextualidade, a paródia (tanto no sentido de canto paralelo como de contracanto) aciona ativamente e criativamente a tradição que parodia. Consequentemente, estudar tal articulação significa estar atenta ao movimento comparativo entre códigos, textualidades, leituras e tradições literárias, de modo a reconhecer os efeitos da paródia também imbricados em um contexto mais amplo de metaficção.
\end{abstract}

Palavras chave: Jane Austen, Gótico, paródia, metaficção.

JANE AUSTEN'S PARODIC RECODIFICATION OF THE GOTHIC IN NORTHANGER ABBEY

\begin{tabular}{|l|l|l|l|l|}
\hline Ilha do Desterro & Florianópolis & n 62 & p. 075-98 & jan/jun 2012 \\
\hline
\end{tabular}




\begin{abstract}
:
The purpose of this essay is to discuss the constructions and effects of the parodic dialogue Jane Austen's novel Northanger Abbey (1818) establishes with a tradition of Gothic literature in the eighteenth-century English context. Because it is considered as an expressive form of intertextuality, parody (both in the sense of 'parallel song' and 'counter-song') actively and creatively recodifies the tradition it parodies. As a consequence, studying such an articulation means being aware of a comparative interplay among codes, textualities, readings and literary traditions, so as to recognize the effects of parody as also articulated with a larger context of metafiction.
\end{abstract}

Keywords: Jane Austen, Gothic, parody, metafiction.

Northanger Abbey (em português, A abadia de Northanger), romance de Jane Austen, publicado postumamente em 1818, foi escrito ainda no final do século XVIII (1798). ${ }^{1}$ Esta discrepância entre tempo de produção e tempo de publicação é relevante para percebermos que já em suas narrativas iniciais havia um grau de consciência muito forte quanto aos parâmetros estéticos que iriam reger suas obras consideradas mais maduras, a serem escritas depois (a exemplo de Emma, publicado em 1816, e Persuasão, seu último romance, também publicado em 1818). Este grau de consciência estética, em Northanger Abbey, justifica-se pelo uso que Austen faz da metalinguagem e da metaficção (algo inovador para a época, embora já experimentado por Laurence Sterne no contexto de literatura inglesa) e do uso de uma voz narrativa que frequentemente interfere com comentários ao leitor, fazendo-se presente em primeira pessoa (a narrativa do romance é em terceira pessoa, com intrusão do narrador). Não bastassem tais estratégias, Austen ainda aprofunda o dado metaficcional através da ironia e da paródia.

Outro aspecto que merece destaque, quando comparamos este romance com os outros da autora, é o fato de a aprendizagem da 
protagonista estar atrelada, em grande escala, às suas percepções, em geral, equivocadas, sobre as relações entre literatura e vida. Nos outros romances, a exemplo de Orgulho e Preconceito, Mansfield Park e Emma, a aprendizagem da heroína depende substancialmente da convivência com o protagonista masculino. Tomando tal diferença como ponto de partida, podemos considerar Catherine (a protagonista de Northanger Abbey), como antecessora de Emma, que, por não se contentar com a monotonia de sua vida, divertiase imaginando enredos mais interessantes para os outros. No caso de Catherine, são as leituras de enredos literários e góticos que aguçam sua fantasia.

A narrativa conta a história desta heroína - Catherine Morland —, de apenas quinze anos, e sua experiência em Bath, para onde ela viaja com os Allens, logo no início do romance; na segunda parte, é a viagem a Northanger Abbey e sua convivência com os Tilneys que constituem as fontes de suas descobertas, decepções e dores. $\mathrm{O}$ leitor logo percebe que não se trata (creio que nunca o é) apenas de travessias geográficas, ou viagens de lazer; na verdade, trata-se de travessias rumo ao autoconhecimento, a um discernimento sobre a vida, as pessoas, os sentimentos, travessias que forjam um amadurecimento emocional e subjetivo. Ou seja, a viagem a Bath e a Northanger Abbey são o seu rito de iniciação: é lá, nestes lugares, que Catherine, enfim, é exposta à realidade de fato, à vida em um nível maior de complexidade.

Jane Austen é famosa pela forma como inicia seus romances, com parágrafos que já condensam muito do tom da narrativa. Neste romance, o parágrafo inicial, em forma de sumário (a narrativa, como dissemos, é em terceira pessoa, com intrusão significativa do narrador), é bastante longo, com informações sobre Catherine e seu contexto familiar. As primeiras linhas dizem: "Ninguém, que tivesse 
alguma vez visto Catherine Morland em sua infância, iria supor que ela houvesse nascido para ser uma heroína" (NA, p. 1). ${ }^{2}$ É uma declaração contundente que ilustra o modo indireto como Austen constrói suas narrativas. Neste caso, há uma explicitação, através da metalinguagem, do caráter de construção da narrativa. O narrador já inicia chamando a atenção do leitor para o fato de que narrativas são construídas; nesta, a despeito de seu perfil, Catherine será a heroína. E que perfil inadequado é este? E qual seria a caracterização apropriada de uma heroína? E por que, não tendo nascido para ser uma heroína, ela o será? Que tipo, então, de heroína ela será?

Estas são questões que lançam o leitor para dentro da construção narrativa, fazendo-o perceber, desde o início, a força metalinguística do romance. Embora a metalinguagem esteja presente em todos os outros romances de Austen, neste, o recurso metalinguístico vem associado, especificamente, à metaficção e à paródia, ao entrelaçamento entre convenções literárias diferentes, constituindo-se em aspecto intrínseco e estrutural da narrativa, como veremos adiante.

Em uma carta escrita a sua sobrinha Fanny Knight, Austen certa vez confessou ter uma aversão a "retratos/representações de perfeição", dizendo que os mesmos faziam-na sentir-se "doente e perversa" (apud MORGAN, p. 109). Sua escolha, portanto, era pelo humano. As descrições dadas no primeiro capítulo de Northanger Abbey mostram a ausência de "heroísmo" na família Morland e em Catherine, cuja caracterização ressalta traços de simplicidade e de ordinário, além de sua identificação com as brincadeiras de meninos, sua lentidão para aprender o que quer que seja e a consequente inaptidão para tornar-se uma accomplished lady, como convinha à ideologia da domesticidade, característica da sociedade pré-vitoriana. A recorrência de uma isotopia ${ }^{3}$ do "não-heróico" ou do "ordinário" (são oito as ocorrências) perpassa todo o capítulo, constituindo-se, ao mesmo tempo, índice 
que aponta para as escolhas narrativas do romance que estamos lendo (Northanger Abbey) e para as diferenças entre este romance e uma tradição anterior (a exemplo daquela dos romances sentimentais e góticos), que, paradoxalmente, será ao mesmo tempo celebrada e parodiada.

Dentro do contexto da metaficcionalidade, uma questão fundamental no romance diz respeito ao consumo de literatura e seus efeitos. Ainda no primeiro capítulo, a voz narrativa informa, com bastante ironia, que dos quinze aos dezessete anos, Catherine "estava treinando para ser uma heroína"; para tanto, "ela lia todas aquelas obras que as heroínas deviam ler para prover suas memórias com citações que eram demasiado úteis e confortantes para as vicissitudes de suas vidas agitadas" (NA, p. 3). A ironia desta passagem pode ser apreendida em níveis diversos: primeiro, há uma sugestão de paralelismo entre as heroínas da literatura e as heroínas (cujas vidas nada tinham de agitadas) da vida real (vida real no nível diegético do romance), e a ponte entre ambas é possibilitada pelo consumo de uma literatura que endossa representações de feminilidade bem cotadas no mercado de casamento. Segundo, a ação artificial contida no verbo "treinar" e no processo de consumir literatura para "memorizar" passagens edificantes ironiza a "aura" de complexidade da literatura, ressaltando a superficialidade do seu uso, atribuindolhe uma mera função utilitária; a consequência disto será o grau de superficialidade da própria "heroína", definida com parâmetros de verniz e aparência, típicos da accomplished lady. Porém, por tratarse de um romance de Jane Austen, o horizonte de expectativa do leitor logo o adverte de que o "treinamento" de Catherine será complexo e ambíguo, afinal, ela é a heroína (talvez devêssemos dizer, anti-heroína) do romance que ele tem nas mãos. Portanto, os efeitos da metaficcionalidade acontecerão duplamente: primeiro, 
no contexto diegético do romance, na articulação construída entre os personagens e o consumo ou apreciação de textos, pertencentes a fontes e expressões diversas - literatura, artes visuais (pintura/ desenhos/sketches). Segundo, na duplicação que a apreensão daqueles sentidos deflagra quando consideramos a função do leitor dentro do texto - ou seja, através da apreensão dos personagens como leitores - comparada com a função do leitor que lê o livro de fora. Por serem leitores pertencentes a contextos históricos e culturais distintos, a comparação entre os dois tipos de leitores torna ainda mais complexo o processo de leitura.

A complexidade dos recursos metaficcionais em Northanger Abbey está diretamente relacionada ao tipo de texto literário que Catherine mais aprecia - a literatura denominada sentimental e gótica, representada, naquele contexto, principalmente por Ann Radcliffe e o seu romance The mysteries of Udolpho (1794). Em linhas gerais, trata-se de uma literatura habitada por seres monstruosos e estranhos, a exemplo de vampiros, fantasmas, esqueletos; uma literatura caracterizada por enredos mirabolantes e espetaculares, guiados por princípios de suspense e efeitos de horror; histórias que têm como fundamento elementos de mistério, crueldade, tortura, tirania, acontecendo em espaços escuros, opressivos, fantasmagóricos. A origem etimológica do termo - "historicamente, os 'Goths' eram uma das várias tribos germânicas que participaram da queda do império romano" (PUNTER e BYRON, p. 3) - é determinante para os significados que o epíteto gótico vai adquirindo ao longo dos tempos: invasor, destruidor; inimigo da civilização; irracional, primitivo; desordenado; bárbaro (PUNTER e BYRON, p. 3-4). No contexto da literatura inglesa do século XVIII, o gênero gótico oferece oposição aos parâmetros de razão e racionalidade característicos do século das luzes e, ao produzir uma literatura em que o estranho (seja 
através de monstros, vampiros, fantasmas) se faz presente, contribui para questionar "as certezas do progresso humano" (PUNTER e BYRON, p. 10), preconizadas pelos seguidores da literatura clássica. Procuraremos observar, na presente discussão, quais elementos do romance de Radcliffe (e, consequentemente, do universo sentimental e gótico) serão reativados através do olhar paródico de Austen. Antes, no entanto, gostaríamos de resssaltar que a metaficção, em Northanger Abbey, não se reduz ao diálogo intertextual com a tradição gótica do século XVIII, sendo ampliada através da inclusão de outras vozes e referências a outros estilos literários. ${ }^{4}$

É relevante sublinhar que já no capítulo segundo do romance Northanger Abbey, quando Catherine parte para Bath, a voz narrativa parodia certo tipo de literatura sensacionalista, direcionada mais para consumo imediato que para a reflexão crítica. Ao relatar a viagem, o narrador informa sobre a tranquilidade e segurança da mesma, e ironicamente acrescenta a informação de que os viajantes (os Allens e Catherine) não foram "agraciados nem com a presença de ladrões nem de tempestades, ou sequer tiveram a sorte de se depararem com um herói” (NA, p. 7). A incorporação de tais elementos, e, ao mesmo tempo, o intuito de negá-los, na presente situação, é o que caracteriza a paródia, definida, a partir de Linda Hutcheon, como "imitação caracterizada por inversão irônica" (1985, p. 6). Neste caso, o dado metalinguístico, presente no comentário do narrador, indiretamente alude, de maneira auto-referencial, ao distanciamento entre as narrativas de suspense e seus efeitos mirabolantes e esta que o leitor ora lê, centrada na experiência mais ordinária e rotineira.

E eis que a "nossa heroína" - como o narrador a denomina ao longo da narrativa - expressão que explicita as presenças do narrador e do narratário/leitor no jogo ficcional (ou metaficcional), finalmente chega a Bath e começa a frequentar as festas e os eventos sociais. 
A princípio, vivencia certo desapontamento, pois não conhece as pessoas do lugar; mas a situação logo muda quando conhece Henry Tilney, descrito como possuidor de um "olhar muito inteligente e ativo, e, se não um cavalheiro muito bonito, quase perto de sê-lo [...]; alguém que falava com fluência e espírito [...]" (NA, p.12). A conversa inicial entre os dois já revela o teor cultural da vida daquele grupo social, que frequentava as danças, o teatro e o concerto ( $N A, \mathrm{p}$. 13). A eventual referência (ainda que irônica), por parte de Henry, ao conteúdo do diário de Catherine, no que se refere a sua mais recente amizade (ele próprio), é significativa para indiciar todo um contexto histórico que relaciona diários e cartas ao registro de experiências privadas femininas. De acordo com Henry, "é o hábito prazeroso de manter um diário que amplamente contribui para formar o estilo de escrita pelo qual as mulheres são tão celebradas" ( $N A$, p. 14). E acrescenta: "Todos admitem que o talento para escrever cartas agradáveis é peculiarmente feminino" (NA, p. 14). Catherine leva certo tempo para apreender o senso de humor de Henry, seu modo quase sempre ambíguo, porque irônico, de se comunicar e seu modo indireto de questionar supostas verdades e convenções.

Muito dos significados ideológicos das narrativas de Austen é filtrado através dos diálogos, fontes substanciais de informações sobre os personagens. É através dos diversos discursos, dicções e vozes que o leitor vai gradualmente apreendendo a complexidade ou superficialidade dos personagens, seus traços psicológicos, ideológicos e humanos. Lembremo-nos, a propósito, do argumento de Mikhail Bakhtin (1993), a respeito da pessoa que fala no romance: “a representação artística do discurso - o discurso do sujeito falante no romance não é apenas transmitido ou reproduzido, mas representado artisticamente" (p. 135). Trata-se de um argumento potente em favor da observação da construção dos vários discursos e 
não apenas do conteúdo que explicitam, em favor da sua adequação para dizer aquilo que dizem. Isto porque, na materialização de tais dicções, podemos encontrar não apenas informações diretas, de cunho tangível, mas sobretudo visões complexas de mundo, posicionamentos diante da vida. Ainda de acordo com Bakhtin (1993), "a ação do herói/personagem no romance é sempre sublinhada por sua ideologia: ele vive e age em seu próprio mundo ideológico, tendo sua própria concepção de mundo, personificada em sua ação e sua palavra" (p. 137); desta forma, o acesso que temos a tal ressonância ideológica faz-se através da análise das palavras, do discurso, enfim, da palavra tornada artística (p. 138), seja a palavra dos personagens, seja a palavra do narrador.

No caso dos diálogos entre Catherine e Henry, o leitor imediatamente percebe uma discrepância entre a rapidez de raciocínio de Henry, seu senso de humor, sua segurança em se expressar, sua ironia, e toda a hesitação de Catherine, expressa através de seus silêncios, suas dúvidas quanto ao que dizer ou mesmo como se comportar: "Catherine virou a cabeça, sem saber se deveria sorrir" (NA, p. 14). Há vários momentos em que Henry comenta sobre determinadas escolhas lexicais ("nice" e "amazingly", por exemplo) de Catherine - usos linguísticos que a Henry parecem inadequados naquele contexto; vê-se claramente o domínio que ele possui sobre a linguagem, algo que contrasta com a ignorância de Catherine. A diferença entre os dois ganha realce quando da chegada de Isabella e John ao círculo de amizades de Catherine, visto que ela não sabe lidar com a manipulação do discurso a serviço da mentira ou da hipocrisia. O jogo cruel que Isabella e John infligem a Catherine é logo percebido por Henry (e pelo leitor). No entanto, Henry é extremamente cuidadoso quanto aos ensinamentos que tenta transmitir a ela, procurando agir de uma forma que a leve a 
descobrir a manipulação exercitada pelos supostos amigos, por ela própria, através da observação dos indícios oferecidos. A maneira como Catherine e Henry se relacionam com a linguagem torna-se complexa à medida que ficam mais íntimos e podem conversar sobre seus gostos literários e artísticos.

A este respeito, o capítulo XIV do romance - quando Catherine, Henry e Eleanor passeiam pelo countryside inglês - é emblemático, na medida em que expõe a ignorância de Catherine, seja quanto ao que Henry avalia como um uso inadequado da linguagem, seja quanto aos seus gostos limitados de leitura, ou quanto à sua incapacidade para a apreciação da paisagem (landscape). Talvez este seja o capítulo mais importante do romance para ilustrar a distinção significativa entre a competência intelectual para criticar e julgar atividades consideradas artísticas ou culturais - uma habilidade normalmente referendada, àquela época, como masculina - e a aprendizagem de tais atividades, necessárias à educação da accomplished lady. Em texto intitulado "Elegant females and gentleman connoisseurs", Ann Bermingham (1995) oferece argumentos bastante substanciais para a compreensão desta divisão pedagógica, que tem como premissa a crença de que "as mulheres aprendem fazendo, enquanto os homens aprendem olhando" (p. 489). E, de fato, se uma função crucial da aquisição de conhecimentos e práticas artísticas - tais como tocar piano, pintar, desenhar - era "mascarar o status da mulher como mercadoria" (p. 491), a realização de tais atividades permitia o jogo voyeurístico em que a mulher era exposta, e o homem exercitava seu desejo de olhar, sem que tais atitudes fossem censuradas, visto que, segundo Bermingham (1995), o desejo era deslocado para uma suposta avaliação estética (p. 491).

Em todos os romances de Jane Austen - e de modo especial, em Pride and Prejudice (Orgulho e Preconceito) - , percebemos que há 
uma crítica contundente à ideologia dos accomplishments. Que leitor de Austen não se lembra da definição que Miss Bingley oferece da accomplished lady como "uma mulher que deve ter um conhecimento geral de música, canto, desenho, dança e línguas modernas"? ( $P P$, p. 85). No entanto, a ocasião serve de motivo para Elizabeth (a protagonista do romance) veementemente rejeitar tal rótulo: " $\mathrm{Eu}$ nunca vi tal mulher. Nunca vi tal capacidade, e gosto, e aplicação, e elegância, como vocês descrevem, juntos" ( $P P$, p. 85). Austen, através do discurso de Elizabeth, e através do comportamento das demais protagonistas, que nunca tiram proveito dos seus "talentos" artísticos para se exibirem, não só denuncia a condição das mulheres num contexto maior de (falta de acesso à) educação, mas apresenta a questão em sua complexidade e ambiguidade.

A questão adquire uma densidade maior em Northanger Abbey, já que, como vimos, Catherine nem de longe se assemelha à caracterização da accomplished lady. Sendo (juntamente com Fanny Price, de Mansfield Park) uma das protagonistas mais jovens dos romances de Austen, Catherine ainda precisa aprender sobre a existência de pessoas que mentem, fingem, enganam, manipulam (a exemplo de Isabella e John Thorpe). As experiências sociais, culturais e afetivas a que é exposta em Bath são determinantes para tal aprendizado. Um exemplo significativo, e que tem relevância dentro da caracterização metaficcional do romance, diz respeito aos diálogos que Catherine mantém com John e Henry sobre suas leituras literárias. No capítulo VII, quando Catherine pergunta a John se ele já havia lido Udolpho, a resposta é: "Udolpho! Oh, Deus do céu! Eu não; eu nunca leio romances; eu tenho mais o que fazer" ( $N A$, p. 35). Em sua limitada visão, romances são textos cheios de bobagens e, como tal, são mais apropriados para a apreciação (ou diversão) feminina. $\mathrm{O}$ diálogo é importante não apenas para denunciar o preconceito, mas 
para expor a própria ignorância de John, que, em momento posterior, admite que "se fosse para ler algum romance, teria que ser de Ann Radcliffe", já que "seus romances são divertidos e valem a pena ser lidos" (NA, p. 36). E quando Catherine lhe responde, constrangida, que Udolpho foi escrito por Ann Radcliffe, John desconversa, age como se tivesse se confundido e continua a denegrir a imagem de outros romances e outras autoras.

$\mathrm{O}$ assunto é retomado capítulos depois, especificamente no capítulo XIV, agora através de um diálogo entre Catherine e Henry. Catherine está passeando com os Tilneys, no countryside (Beechen Cliff) ao redor de Bath, quando menciona que aquela região a faz lembrar o sul da França. A conclusão imediata de Henry é que ela já tenha viajado para fora da Inglaterra. Porém, como ela mesma informa, trata-se de uma associação construída através de suas leituras do romance The mysteries of Udolpho, que oferece descrições daquele espaço geográfico, tão claramente fixado em sua memória, que agora volta à tona. ${ }^{5} \mathrm{E}$, de modo conclusivo, Catherine pergunta a Henry: "Mas você nunca lê romances, eu diria?" (NA, p. 94). O leitor logo relembra o diálogo anterior entre Catherine e John Thorpe. Só que, desta vez, a resposta que Henry oferece é completamente diferente: "a pessoa, seja cavalheiro ou dama, que não sinta prazer com a leitura de algum romance, deve ser intoleravelmente idiota" (NA, p. 95). Sua resposta aponta para um nível de cumplicidade a ser desenvolvido posteriormente entre eles - cumplicidade com a literatura, que acaba por oferecer testemunhos significativos a respeito dos contextos de suas leituras - contextos permeados pela sensação de prazer, decorrente do suspense que a narrativa gótica oferece; leituras feitas em voz alta, de Henry para sua irmã Eleanor; interrupção intencional da leitura, em momento-chave da narrativa, a fim de acirrar o interesse do leitor. 
Em todo o capítulo XIV, Austen faz uma homenagem aos leitores e aos atos de leitura (e, claro, por extensão, aos escritores e suas produções, e não apenas as literárias). Por exemplo, quando o assunto transita pelos conteúdos de história (nas palavras de Catherine, "real, solemn history/a história real, solene" (NA, p. 97), duas visões antagônicas são apresentadas: de um lado, Eleanor, e sua apreciação prazerosa da história; de outro, Catherine, e sua crítica a uma visão histórica que se concentra em "disputas de papas e reis, com guerras e pestes em toda página"; em que "os homens são todos bons, sem razão para tal, e onde as mulheres praticamente não aparecem [...]" (NA, p. 97). Catherine conclui sua avaliação aludindo à questão do conteúdo ficcional dos textos históricos: "e, no entanto, eu frequentemente me pergunto por que a história é tão chata, já que em grande parte deve ser invenção" (NA, p. 97).

A fala de Catherine é não apenas contundente, mas atual, e exige que destaquemos ao menos três aspectos: há uma história não-contada e não registrada de pessoas comuns (a exemplo das mulheres), que vivem um cotidiano comum e aparentemente sem relevância para ser documentado; a história oficial - "real e solene", para usar os atributos mencionados acima - não soa, de fato, verdadeira, porque é distante e parcial, embora apresentada de modo aparentemente homogêneo; o teor de fantasia e invenção inerente à história não atrai Catherine, em oposição ao efeito que a invenção literária lhe provoca. Deste modo, para Catherine, a literatura torna-se mais atraente e real (diríamos, pulsante e verossímil) que a História. É por isto que o aprendizado de Catherine é, em grande escala, determinado por sua experiência como leitora (ainda que, por enquanto, seja apenas de literatura gótica). Neste sentido, os capítulos do romance que se concentram na abadia (não é à toa que a referência "Northanger Abbey" tenha sido escolhida para o título 
do livro) são decisivos para a compreensão da subjetividade da personagem e para uma investigação das estratégias metaficcionais e seus efeitos.

Diferentemente de Susan Morgan, para quem o romance enfraquece quando a ação narrativa passa a acontecer na abadia, sobretudo quando Catherine começa a suspeitar do general como assassino de sua esposa (MORGAN, 1986, p. 115), considero estes capítulos cruciais não apenas para a definição da complexidade subjetiva de Catherine, mas principalmente por explicitar o poder da literatura, da fantasia, da fabulação, constituindo-se em diferença significativa em relação aos demais romances da autora. Os capítulos do livro que se referem às interações entre os personagens na abadia são exemplos da consciência literária de Austen, do conhecimento que ela tinha da literatura de seus contemporâneos e, portanto, contribuem para referendar também sua experiência de leitora. A propósito, sua homenagem a autoras como Frances Burney e Maria Edgeworth já aparecem no capítulo $\mathrm{V}$ do romance, quando a voz narrativa faz referência a Cecilia, Camilla e Belinda. ${ }^{6}$

Em Northanger Abbey, podemos testemunhar a articulação que Austen promove entre diferentes convenções literárias, através da paródia e da ironia. As marcas metaficcionais vão desde referências literárias da literatura gótica - a exemplo do romance The mysteries of Udolpho - a considerações de contextos e propósitos de leitura, que demandam uma reflexão sobre a intencionalidade da paródia. Segundo Linda Hutcheon (1985), a própria etimologia do termo paródia abarca os sentidos de "contracanto" e "canto paralelo" (p. 32). No presente caso, seria simplista dizer que Austen parodia a literatura gótica, sem discutir os efeitos decorrentes do processo de recodificação e re-significação aí implicados. E se a paródia implica uma re-escrita, um processo de confrontação entre textos, faz-se 
necessário analisar a materialização da paródia em termos formais, como diálogo de códigos partilhados, bem como sua função como produto histórico (HUTCHEON, p. 24).

Tal complexidade inerente à expressão da paródia já pode ser ilustrada através do diálogo entre Catherine e Henry, na ida à abadia. Quando Catherine pergunta a Henry se a abadia é mesmo "um lugar interessante e antigo, exatamente como aqueles que se leem a respeito" (NA p. 142), o leitor (e claro, Henry) logo percebe(m) o parâmetro de suas expectativas. É o estímulo de que Henry precisa para divertir-se com a Catherine-leitora de estórias sentimentais e góticas; para o leitor, trata-se de um convite para a compreensão da paródia como "uma abordagem produtiva e criativa em relação à tradição" (HUTCHEON, 1985, p. 7). Henry logo se transforma em um narrador de literatura gótica, antecipando para Catherine - a leitora ávida e altamente motivada - "todos os horrores que uma construção igual 'a uma que se lê a respeito’ pode produzir” (NA, p. 142).

Em sua "narrativa", Henry refere-se ao isolamento do quarto designado para Catherine; ao fato de que a mesma será guiada por Dorothy, uma das serviçais da casa, por diferentes escadas e muitos corredores sombrios; também diz que seu quarto é igualmente escuro, com as paredes cobertas de tapeçaria, que exibem figuras grandiosas como a vida, e a cama coberta com material verdeescuro e veludo roxo, tendo, inclusive, uma aparência funerária ( $N A$, p. 142). Henry faz referência à adequação da mobília (arca, baú, armário) com a atmosfera mal-assombrada e enigmática do quarto, que, embora apresentando perigos ao hóspede, não possui chave (NA, p. 143) - o que potencializa, portanto, a sua vulnerabilidade e risco. A narrativa é enriquecida com alusões a tempestades e trovões tão violentos que farão o edifício tremer e o barulho ecoar pelas montanhas vizinhas (NA, p. 143). Há uma gradação de suspense 
em seu processo de contar, culminando na referência a passagens subterrâneas, catacumbas, e à presença de espadas, gotas de sangue e instrumentos de tortura (NA, p. 144).

À medida que Henry vai narrando, Catherine vai reagindo com expressões do tipo: “Oh, Mr. Tilney. Quão aterrorizador! É exatamente como no livro! Mas isto não vai acontecer comigo de verdade [...]" (NA, p. 143). Ao mesmo tempo, Catherine pede a Henry que continue. Henry se aproveita da reação ambivalente de Catherine, que, mesmo não acreditando de todo em sua narração, responde com interesse e motivação, incitando-o a prosseguir. Percebe-se que o "narrador Henry" não apenas conta uma estória, mas o faz de modo consciente e atento aos ingredientes que compõem aquele universo narrativo, de modo a manter aceso o interesse de sua "leitora". Sem dúvida, trata-se de um processo em que a leitura e a narração - e, consequentemente, a escuta - se revelam eróticas em sua função; e isto de modo duplo: primeiro, para os personagens envolvidos; segundo, para o leitor que lê o romance de fora (quando comparamos com os leitores que se encontram dentro do romance, como Catherine e Henry), que percebe (diferentemente de Catherine) as estratégias irônicas utilizadas por Henry.

$\mathrm{O}$ aspecto de prazer suscitado pelo processo de contar e ouvir está intimamente associado, em Northanger Abbey, à educação, ao processo de aprendizagem por que passa a heroína. Ou seja, além de narrador (neste momento específico do romance), Henry também responde pela função de educador no processo de amadurecimento psicológico de Catherine. E a duplicação que a estratégia de mise en abyme provoca - ao inserir a literatura sentimental e gótica em um contexto cômico-realista, dando origem a vozes narrativas distintas, convenções literárias incongruentes, enredos e conflitos semelhantes aos daquela literatura - nos faz pensar no componente ideológico 
(ridicularização, subversão, homenagem) da própria paródia, seja no plano estrutural da narrativa, seja no contexto amplo das próprias convenções literárias.

Vejamos inicialmente o primeiro nível, o da estrutura narrativa. Quando chega à abadia, Catherine decepciona-se com o ar de normalidade e modernidade da mesma; percebe que seu quarto não corresponde à descrição aterrorizadora oferecida por Henry. Ainda assim, guiada por seus parâmetros de literatura gótica, não perde a chance de fantasiar a partir de algumas peças da mobília, a exemplo de uma arca e um armário, presentes em seu quarto. Imagina, por exemplo, ao observar e tentar abrir a arca, que o móvel deve guardar algum segredo. Tempos depois, investigando um armário, descobre o que supõe serem manuscritos, signos portadores de mistério, necessitando, portanto, de decifração. $\mathrm{Na}$ verdade, descobre posteriormente que se tratava apenas de ordinárias anotações, contas, listas de corriqueiras atividades domésticas. As explorações e investigações de Catherine decorrem do poder de sua imaginação, estimulada por suas leituras de romances góticos. Mesmo que os ambientes da abadia, por um lado, demonstrem uma habitação normal, completamente distanciada das descrições oferecidas por Henry ou por outros narradores lidos por Catherine em romances, ela não se rende à normalidade e insiste na fantasia. Para corroborar suas investidas, a noite apresenta-se tempestuosa, com chuva e ventos ruidosos (NA, p. 151), cenário perfeito de uma atmosfera gótica, e, portanto, convite irresistível a seus devaneios.

$\mathrm{Da}$ análise da mobília, Catherine passa a observar o comportamento de General Tilney, cuja violência, em algumas de suas falas, faz Catherine tremer, empalidecer e ficar sem fôlego (NA, p. 150). Seu comportamento autoritário e opressor serve para desencadear, em Catherine, suspeitas sobre sua relação com 
a Sra. Tilney, a ponto de ela imaginar que ele ou mantém a esposa encarcerada na abadia, em algum quarto escondido, ou mesmo que possa ter provocado sua morte. Para acirrar suas suspeitas, Catherine faz várias perguntas a Eleanor sobre a morte da sua mãe, a Sra. Tilney. Quando Eleanor lhe diz que não estava presente quando a mãe morreu e que tudo aconteceu de modo inesperado e abrupto (NA, p. 171), Catherine decide - rompendo com as regras impostas, já que o acesso ao quarto não era permitido - investigar possíveis marcas e vestígios deixados no quarto do casal. Nesses capítulos da narrativa, Catherine age e se comporta como uma heroína de literatura gótica; para ela, a abadia esconde alguma história de horror, algum crime hediondo, e, consequentemente, um assassino e sua vítima. Quem mais, além de Catherine, poderia solucionar tal mistério?

A complexidade advinda da confluência entre os diferentes níveis de leitura (não só as interpretações de Catherine, mas suas leituras em comparação com a interpretação mais geral que a narrativa oferece) atinge o ápice quando Henry a surpreende no quarto de sua mãe e tenta lhe abrir os olhos, trazendo-a de volta para a vida real:

"Minha querida Srta Morland, considere a natureza aterrorizadora das suspeitas que você vem alimentando. Você vem julgando a partir de que? Lembre-se do país e da época em que vivemos. Lembre-se de que somos ingleses: de que somos cristãos. Observe sua própria compreensão, seu senso do provável, sua própria observação daquilo que se passa a seu redor. Será que a nossa educação nos prepara para tais atrocidades? Será que as nossas leis são coniventes com tais atrocidades? (...)" (NA, p. 182).

Neste momento, Henry refere-se à suspeita que Catherine havia alimentado de que seu pai poderia ter torturado e assassinado sua 
mãe, a Sra. Tilney. É como se ele lhe dissesse: "Catherine, não estamos em um enredo ou contexto de literatura gótica, onde tal fantasia poderia possuir veracidade". Diante da lição de Henry, Catherine sente-se humilhada, e "com lágrimas de vergonha, corre em direção a seu quarto" (NA, p. 182). De modo significativo, o capítulo posterior inicia com a seguinte frase: "As visões romanceadas tinham chegado ao fim" (NA, p. 183), numa clara referência ao fato de que Catherine, agora, encontra-se "curada" de sua exacerbada imaginação fantasiosa.

E o que passamos a testemunhar a partir deste momento? Como interpretar o fato de que a personagem foi podada em seu poder imaginativo? O que está por trás da lição de racionalidade de Henry? Sim, porque seu discurso é todo permeado por termos relacionados ao campo semântico da razão, a exemplo de "julgar"; "compreender"; "senso do provável"; "observação" (NA, p. 182). Como compreender seu discurso quando o inserimos na narrativa maior de Austen, e quando também consideramos, como leitores, que precisamos acionar nossa imaginação, nossa capacidade de fantasia, nossa liberdade de devaneio? Como podemos conciliar a "punição" sofrida por Catherine e a defesa implícita do poder da literatura (consequentemente, da fantasia, da imaginação) que o romance oferece? Ora, é exatamente nesse momento que se faz necessário problematizar o sentido ideológico do gótico e a re-significação que Austen promove do mesmo.

Dois fatos contribuem para o modo complexo e ambíguo com que Jane Austen lida com a questão. Primeiro, através da carta do irmão (James), Catherine toma conhecimento da participação de Captain Tilney no rompimento entre James e Isabella. Por ser uma irmã afetuosa e amorosa, ela sofre com o sofrimento do irmão. Segundo, ao ser expulsa da abadia pelo General Tilney, que descobriu que ela não era a herdeira rica que ele imaginara, Catherine vivencia, 
novamente, momentos de aflição e de dor. É humilhada e forçada a voltar para casa sozinha, cedo da manhã, tendo que enfrentar o medo. Em ambas as situações, Catherine tem a oportunidade de vivenciar um sofrimento real; não são atrocidades o que Captain Tilney e General Tilney cometem?

Desta forma, conclui-se que Catherine não avaliou tão equivocadamente assim a maldade e crueldade de General Tilney. Ao perceber a arrogância, frieza e autoritarismo do General, Catherine faz dele um retrato semelhante ao de um personagem cruel, frio, facilmente identificado com os vilões de sua memória literária gótica. É por isto que a lição pedagógica de Henry também adquire um tom altamente irônico, capítulos depois na narrativa; Henry e seu discurso também são alvo da paródia mais ampla de Austen. Quando seu pai expulsa Catherine de casa, da forma mais hostil, humilhante e cruel possível, apenas por ter descoberto que ela não era a herdeira rica que ele imaginara, seria a vez de Henry rever sua avaliação sobre a educação, liberdade de imprensa e as leis existentes em seu país. ${ }^{7}$ Então os ingleses, também definidos por Henry como cristãos, não cometem atrocidades? Percebe-se que o discernimento e a racionalidade de Henry são limitados e, por isto, também podem ser incluídos como alvo da paródia de Austen. É como se, implicitamente, a narrativa nos dissesse que embora aquele não seja um enredo gótico, também é habitado por seres "monstruosos" e horrendos. O "gótico" não se encontra tão distante da suposta vida comum.

Quando pensamos na expressão e efeitos da paródia a partir do diálogo produzido com as convenções literárias, é necessário reconhecer as questões de autoria e autoridade tais como exercitadas por Austen. No início desse texto, aludimos ao fato de que Northanger Abbey, embora um dos primeiros romances escritos pela autora, só 
foi publicado postumamente. No entanto, tal fato não compromete a maturidade estética do mesmo, sobretudo quando consideramos a utilização complexa que Austen faz dos recursos irônicos aliados à paródia da literatura sentimental e gótica. Segundo Linda Hutcheon (1985), a paródia reflete uma necessidade do artista de responder às convenções literárias anteriores e ao passado (p. 96). Ou seja, a estratégia paródica implica conhecimento das convenções literárias daquilo que se parodia. Neste caso, é relevante reconhecer o êxito de Austen que, nas palavras de Susan Gubar, "parodia as convenções góticas, ao mesmo tempo em que se baseia nelas para dar forma a seu romance" (apud HUTCHEON, 1985, p. 79). Neste sentido, não há como negar o caráter inventivo e criativo da paródia que, ao promover a reativação de um texto, fincado em um contexto anterior, o faz através do controle do código, com distanciamento crítico, constituindo-se em ato de autonomia e emancipação (HUTCHEON, p. 96). Northanger Abbey, portanto, é um romance que ilustra a consciência literária de Austen, sua vivência da literatura como autora e leitora. Sua paródia do gótico, ao tempo em que desnuda o caráter ficcional da literatura, também é um convite à reflexão sobre a íntima relação entre literatura e vida.

\section{Notas}

1. Segundo Josephine Ross (2007), Jane Austen revisou o manuscrito do romance antes de sua morte (em 1817), e, através de um prefácio, alertou seus leitores sobre a possibilidade de considerarem sua "pequena obra" como datada (2007, p. xxxv).

2. Além da tradução de trechos do romance (cujas referências serão identificadas de modo abreviado, NA; no caso do romance Pride and Prejudice, $P P$ ), também as outras traduções de textos em inglês (ver bibliografia) são minhas. 
3. O termo isotopia, advindo da semiótica de François Rastier, denota "a repetição de uma ideia em um texto através de diferentes níveis e diferentes signos". In: CHILDERS and HENTZI, 1995, p. 161, grifos do autor.

4. Analisar a metaficcionalidade de um texto como Northanger Abbey significa explicitar as estratégias e os recursos de construção textual, a exemplo da intertextualidade, paródia e mise en abyme, possibilitando maior consciência quanto à sua natureza estética e criativa. Obviamente, devido ao escopo do presente texto, não poderemos aprofundar tais aspectos aqui, porque isto demandaria uma discussão mais detalhada da questão da metaficção no romance como um todo.

5. Não é à toa que Catherine seja capaz de construir tal associação. Terry Castle, em "Introdução" ao romance The mysteries of Udolpho, ressalta a habilidade de Ann Radcliffe em suspender a ação narrativa a fim de "pintar paisagens". Segundo a crítica, Radcliffe almejava "atingir na prosa os mesmos efeitos visionários que ela admirava nas obras dos pintores de landscape do século XVII (...)" (CASTLE, 2008, p. xv).

6. Cecilia (1782) e Camilla (1796) são romances de Frances Burney; e Belinda (1801) é um romance de Maria Edgeworth.

7. Todo o discurso de Henry é usado como epígrafe no romance Atonement (2001), do também inglês Ian McEwan. Em texto intitulado "Words, images and invention: the power of metalanguage in Austen, McEwan and Wright", apresentado no Congresso da ABRAPUI em 2009, procuro aprofundar os significados irônicos que o seu discurso suscita em relação ao contexto do romance de McEwan.

\section{Referências bibliográficas}

AUSTEN, Jane. Northanger Abbey. Harmondsworth: Penguin, 1994.

. Pride and Prejudice. Harmondsworth: Penguin, 1985.

AZERÊDO, Genilda. Words, images and invention: the power of metalanguage in Austen, McEwan and Wright. In: Anais do II Congresso Internacional da ABRAPUI. The teaching of English: towards an interdisciplinary approach between language and literature. São José do Rio Preto: Editora da UNESP, 2009. Publicação em CD. 
BAKHTIN, Mikhail. A pessoa que fala no romance. In: Questões de literatura e de estética: a teoria do romance. Trad. BERNADINI e outros. São Paulo: Unesc-Hucitec, 1993, p. 134-163.

BERMINGHAM, Ann. Elegant females and gentlemen connoisseurs. The commerce in culture and self-image in eighteenth-century England. In: Bermingham, Ann \& Brewer, John. (eds.). The consumption of culture 1600-1800. Image, object, text. London and New York: Routledge, 1995, p. $489-513$.

BREWER, John. The pleasures of the imagination. English culture in the eighteenth century. New York: Farrar Straus Giroux, 1997.

CASTLE, Terry. Introduction. In: Radcliffe, Ann. The mysteries of Udolpho. Oxford: Oxford University Press, 2008, p. vii-xxvi.

CHILDERS, Joseph and HENTZI, Gary (eds.). The Columbia Dictionary of Modern Literary and Cultural Criticism. New York: Columbia University Press, 1995.

HUTCHEON, Linda. Narcissistic Narrative: the Metafictional Paradox. New York and London: Methuen, 1980.

. A Theory of Parody. The Teachings of Twentieth-Century Art Forms. New York and London: Methuen, 1985.

MORGAN, Susan. Guessing for ourselves in Northanger Abbey. In: Bloom, Harold (ed.). Jane Austen. Modern Critical Views. New York and Philadelphia: Chelsey House Publishers, 1986, p. 109-128.

PAWLOWICZ, Peter H. Reading women. Text and image in eighteenthcentury England. In: Bermingham, Ann \& Brewer, John. (eds.). The consumption of culture 1600-1800. Image, object, text. London and New York: Routledge, 1995, p. 42-53.

PUNTER, David and BYRON, Glennis. The Gothic. Malden and Oxford: Blackwell Publishing, 2007.

ROSS, Josephine. Northanger Abbey: a Modern Perspective. In: Austen, Jane. Northanger Abbey. Cambridge: The Worth Press. 2007, p. xxxv-xliii.

STAM, Robert. O espetáculo interrompido: literatura e cinema de desmistificação. Tradução de José Eduardo Moretzsohn. Rio de Janeiro: Paz e Terra, 1981. 
98 Genilda Azerêdo, Jane Austen e a recodificação paródica do gótico

WAUGH, Patricia. Metafiction: the Theory and Practice of Self-Conscious Fiction. London and New York: Routledge, 1984.

WILTSHIRE, John. Recreating Jane Austen. Cambridge: Cambridge University Press, 2001.

[Recebido em 26/11/2011. Aprovado em 21/02/2012] 